\title{
Social Media, Open Platforms, and Democracy: Transparency Enabler, Slayer of Democracy, Both?
}

\author{
John Carlo Bertot \\ University of Maryland College \\ jbertot@umd.edu
}

\begin{abstract}
Government agencies have increased their use of social media as a means to connect to and engage with their citizenry, disseminate and promote policies, to inform the public, and in general promote more transparency in government. Recently, however, social media platforms are being used by some inside government to criticize those who do not agree with their policies; circumvent expected administrative, legislative, and judicial processes; and create a policy making process that resides outside constitutional and deliberative channels. Further, as discovered during the 2016 U.S. presidential elections, foreign governments have used social media platforms to interfere with sovereign nation elections through concerted efforts to falsify facts, create false stories ("fake news"), and sow discord among electorates. In the U.S. context, social media wields significant influence on voters, democratic institutions, and the deliberative democratic process. Using the U.S. context, this article presents a preliminary exploration of the emerging perils that social media represents to democracies, from administrative (management and operations of government) and democratic (governance) perspectives.
\end{abstract}

\section{Introduction}

Social tools vary in their design, purposes, and approaches, but they share a focus on fostering communication, interaction, engagement, content sharing, and content creation in a social context $[1,2,3]$. Social media is an umbrella term that refers to a range of web-based technologies, services, and resources designed to create one-to-many and/or many-to-many communication channels and can include both government-specific tools and third party external platforms. The U.S. Office of Personnel Management (OPM) defines social media as "tools and technologies that allow a social media user to share communications, postings or information, or participate in social networking, including but not limited to: blogs (e.g., Twitter, Tumblr), social networks (e.g., Facebook,
LinkedIn, Google+), video and photo sharing websites (e.g., Instagram, Flickr), online forums and discussion boards, and automated data feeds" $[4$, p. 1]. OPM further elaborates, indicating that social media platforms refer to internal and external services such as [4]:

- Social Networking Sites (Facebook, Google+, LinkedIn, etc.)

- Micro-blogging sites (Twitter, Tumblr, etc.)

- Blogs (including OPM official use and nonofficial/personal use blogs, as well as comments)

- Agency User Posts to THEO

- Video and Photo Sharing Websites (Instagram, YouTube, Flickr, etc.)

- Forums and Discussion Boards (non-official and personal use of Google Groups, Yahoo! Groups)

- XML \& RSS Feeds

- Ideation Programs (IdeaScale, IdeaFactory, etc.)

- Online Information Repositories/Encyclopedias for both official use (e.g., Max.gov) and non-official/personal use (e.g., Wikipedia)

- Emerging/new technology identified as social media by GSA's DigitalGov.gov website to help government workers deliver a better customer experience to citizens.

Other federal agencies have similar definitions of social media in general and platforms in particular [e.g., 5, 6]. In addition to these engagement tools, some social media tools have leveraged their platforms to workplace and productivity products such as Workplace by Facebook

(https://www.facebook.com/workplace), and such tools may make their way into the federal government setting.

The many-to-many interaction capabilities of social media allow governments (and others seeking to work with policymakers and impact policy development) to foster collaboration among and between geographically dispersed 
users [7]; leverage crowds [8]; foster innovation [1]; monitor and respond to emergency situations [9]; solve challenging problems by tapping into unique and rare expertise [10]; jointly develop (co-create) government services and resources [11]; and more. These capabilities have offered significant promise in redefining governmentcommunity and government-citizen connections and interactions. But recently, the capabilities of social media technologies have also demonstrated negative aspects in relation to democratic principles and government functions.

The goals of this exploratory paper are to: 1) Identify issues associated with the use and uses of third party social media platforms by the U.S. government; 2) Describe the current policy and legal framework regarding U.S. Federal government use of technologies and data and information management in relation to social media technologies; 3) Provide initial analysis of recent revelations regarding the use of social media platforms to affect U.S. democratic processes; and 4) Offer initial observations, questions, issues that require further exploration and research. The paper makes use of policy and legal analysis techniques, as well as content analysis, to identify the preliminary findings that require furthers study.

\section{Social Media in the U.S. Federal Government Context}

Adopting a forward looking and optimistic stance regarding social media from the beginning, the Obama Administration strongly encouraged agencies to use social media to provide information, communicate with members of the public, and distribute services. The Obama Administration made the use of social media a priority to foster government-citizen interaction and engagement $[12,13]$, as evidenced through its Open Government Directive [14], advancing a digital strategy initiative [15], reports such as the 2009 Open Government: A Progress Report to the America People, and guidance to agencies intended to provide advice regarding the use of social media by agencies within existing federal policies and laws [16]. These efforts provided various directives and guidance on the use of social media approaches to designed to promote transparency, engagement, and technologies across many different agencies.

These actions led to an expectation of government agency adoption of social media technologies, agency engagement of the public via social media, and the use of social media as a means through which to enhance transparency and citizen engagement in government. A net result of the directives to government agencies was a rapid adoption by agencies of social media tools and communication strategies centered around social media use $[17,18,19,20]$.

Although the Trump Administration has issued a report highlighting its science and technology accomplishments during its first year [21], it has not developed or articulated a comprehensive federal government technology vision or plan. One might argue that the Trump Administration has at most updated and incrementally built on the Obama Administration's technology innovations and plans, as evidenced in part by the Digital Government Strategy action items (https://www.gsa.gov/technology/government-itinitiatives/digital-strategy). Further, the Trump Administration has refocused the White House's Office of Science and Technology Policy efforts to center on five key areas: Economy, National Security, Budget, Immigration, and The Opioid Crisis (https://www.whitehouse.gov/ostp/).

An initial assessment would indicate that, as of yet, there is no apparent or emerging federal government social media strategic plan under the current Trump Administration.

\section{U.S. Government Social Media Policies and Laws}

Federal information policies emanate from a range of sources that includes legislation, regulations, directives, memorandums, circulars, and Executive Orders, to name some. Different policy instruments carry different weight and application, but individually and collectively they can govern significantly the ways in which federal agencies operate; engage technologies to disseminate information or offer services; communicate with citizens; and are required to meet expectations for the management, security, privacy, use, reuse, access to, and preservation of government information, services, and resources. 
Table 1 identifies selected federal policies related to federal agency use of social media. While these policy instruments predominantly predate the existence of social media, their reach extends to agency interaction with and use of social media technologies. In April 2010, the Office of Management and Budget (OMB) issued a memorandum on social media, Web-based interactive technologies, and paperwork reduction in order to try and clarify government agency use and obligations regarding social media in relation to the requirements of the Paperwork Reduction Act (PRA) [16]. Major policy goals, however, of privacy, security, data and information accuracy, archiving, access, and inclusion remain largely unaddressed.

The below expands on initial analysis conducted by Bertot, Jaeger, \& Hansen [24], and discusses aspects of selected federal policies in relation to social media to highlight key issues related to federal agency use of social media and compliance with federal policies.

\subsection{Governing and Governance Policies}

Nearly all of the federal government policies related to governing and governance pre-date social media technologies. Overarching principles and requirements, however, transcend technology tools and platforms and still apply. For example, OMB Circular A-130 and the PRA establish principles that require agencies to:

- Disseminate information to the public in a timely, equitable, efficient, and appropriate manner.

- Establish and maintain inventories of information products.

- Develop alternative strategies to distribute information.

- Employ appropriate management and archiving of records.

- Evaluate and determine the most appropriate methods to capture and retain regardless of where the records may reside.

- Consider disparities of access and how those without Internet access will have access to important disseminations.

- Provide members of the public who do not have Internet connectivity with timely and equitable access to information.
A key aspect of the Obama Administration's open government initiatives, promoted extensively by social media, was to provide access to numerous open data sets.

While the Trump Administration has maintained the data.gov portal, it took down the open.whitehouse.gov site, which contained a number of open data sets [25] - with the promise to create a new site to enhance transparency. The site has not materialized, and users are now taken to https://www.whitehouse.gov/disclosures/ and can see financial waiver disclosures - in PDF format rather than in usable datasets - of key White House staff. Further, the Trump Administration removed various datasets and reports from selected websites of key agencies such as the Environmental Protection Agency, the State Department, and the Department of Energy [26].

The above demonstrates a growing disconnect between existing information policies, government use of social media technologies, and government information access and dissemination expectations. Sunstein's OMB Memo [16] attempted to selectively bridge the gaps between existing federal policies and the rapid adoption of social media tools by agencies. The Memo attempted to clarify agency restrictions on the use of social media, while simultaneously easing agency ability to take advantage of social media. The Memo noted that agencies remained obligated to meet the PRA information access, collection, and dissemination requirements.

The above also seems to indicate that there is a shift in the definition and application of open and transparent government in the transition from the Obama Administration to the Trump Administration. Whereas the Obama Administration in general supported the use of social media to extend government information and data dissemination efforts as well as foster transparency, the Trump Administration seems less inclined to foster openness through social media and other technologies. For example, President Obama's Executive Order Making Open and Machine Readable the New Default for Government Information [44], sought to make government data in machine readable formats the default; the release of Administration disclosures in PDF format by the Trump Administration is a step on the opposite direction. 


\begin{tabular}{|c|c|}
\hline Key Policy Goals and Social Media & Selected Relevant Policy Instruments \\
\hline Governing and Governance & $\begin{array}{ll}\text { - } & \text { E-government Act of } 2002 \\
\text { - } & \text { OMB Circular A-130 (Management of Federal Information } \\
& \text { Resources) } \\
\text { - } & \text { Memorandum: Social Media, Web-Based Interactive } \\
& \text { Technologies, and the Paperwork Reduction Act } \\
\text { - } & \text { Paperwork Reduction Act } \\
\text { - } & \text { Various Copyright (Title } 17 \underline{\text { USC)}} \text { ) and Patent \& Trademark } \\
& \text { (Title } 35 \underline{\text { USC) legislation }}\end{array}$ \\
\hline Privacy, Security, \& Data Quality & $\begin{array}{l}\text { - } \text { Children's Online Privacy Protection Act (COPPA) } \\
\text { - } \quad \text { Federal Information Security Management Act (FISMA) } \\
\text { - } \\
\text { OMformation Quality Act } \\
\text { Provisions of the E-government Act of 2002) } \\
\text { - OMB Memo M-04-04 (E-Authentication Guidance for Federal } \\
\text { Agencies) } \\
\text { - OMB Memo M-05-04 (Policies for Federal Agency Websites) }\end{array}$ \\
\hline Archiving and Preservation & $\begin{array}{ll}\text { - } & \text { Federal Depository Library Program (Title } 44 \underline{\text { USC) }} \\
\text { - } & \text { Presidential Records Act } \\
\text { - } & \text { Federal Records Act } \\
\text { - } & \text { Managing Government Records Directive } \\
& \text { National Archives and Records Administration Bulletin 2014- } \\
& \text { 2: Guidance on Managing Social Media Records }\end{array}$ \\
\hline Access and Social Inclusion & $\begin{array}{l}\text { - } \text { Americans with Disabilities Act } \\
\text { - } \\
\text { - Persecutive Order } 13166 \text { - Improving Access to Services for } \\
\text { - } \quad \text { Individuals with Disabilities Education Act } \\
\text { - Section } 504 \text { of the Rehabilitation Act } \\
\text { - Section } 508 \text { of the Rehabilitation Act } \\
\text { - Telecommunications Act of } 1996\end{array}$ \\
\hline
\end{tabular}

Table 1. Selected Information Policies by Objective (updated from [24]).

\subsection{Privacy, Security, \& Data Quality}

The privacy and security concerns raised by social media technologies were a concern from the inception of the platforms given the privacy and data use/reuse policies adopted by social media technology companies - and moreover, the fact that the federal government was willing to use platforms that do not conform to federal privacy and security requirements (e.g., the Privacy Act, the Federal Information Security Management Act) - was noted as problematic previously [24].

Since then, however, evidence has surfaced regarding the inappropriate sharing of Facebook data, for example, with Cambridge Analytica (now in bankruptcy, but before provided data services to the Trump Campaign) and the sharing of Facebook data with multiple phone device manufacturers $[27,28]$. In the case of Cambridge Analytica, estimates are that between 50 and 87 million user profiles were harvested by the company, which also included data about Facebook "friends" contained in those profiles. In short, by adopting the use of specific social media tools, government agencies are endorsing the privacy, security, and other policies and practices employed by those social media providers and one might argue complicit in any violation of federal privacy and security laws and regulations by these companies.

The Information Quality Act (passed into law in 2001) requires agencies to maximize the quality, objectivity, utility, and integrity of information and services provided to the public. The Act came into effect prior to the development and use of prevailing social media technologies and open data portals, nonetheless, agencies must 
ensure reasonable suitable information and service quality strategies consistent with the level of importance of the information that include clearly identifying the limitations inherent in the information dissemination product (e.g., possibility of errors, degree of reliability, and validity) and taking reasonable steps to remove the limitations inherent in the information.

Thus, while federal agencies are required to abide by data and information accuracy and quality frameworks and expectations, what has come to light since the election of President Trump is that social media platforms, Facebook and Twitter in particular, have been leveraged by outside entities to spread false stories and attempt to influence the outcome of the 2016 presidential elections [29].

A recent study by the Pew Research Center indicated that $67 \%$ of Americans get at least some news from social media sites [30]. While Facebook in particular is seeking to take steps to ensure the accuracy of the news items on its platform and has (along with Google and others) joined the Trust Project (https://thetrustproject.org/), the reality is that Facebook, Twitter, and Reddit - to name a few social media platforms - do not meet the information quality assurance specifications required of federal agencies and to date there is no sense of how federal agency information and data sources are being impacted by falsified postings via social media.

Regarding their public websites and social media use, federal agencies are required to conduct privacy impact assessments, post privacy policies in a standardized machine-readable format on each website, and post a "Privacy Act Statement" that describes the Agency's legal authority for collecting personal data and how the data will be used as per OMB Memo M-03-22 (Guidance for Implementing the Provisions of the E-government Act of 2002). Additionally, federal websites are prohibited from using persistent cookies and other web tracking methods unless an Agency head or designated Agency sub-head approved their use for a compelling need. In such cases, agencies must post clear notice of the nature of the information collected in the cookies, the purpose and use of the information, whether or not and to whom the information will be disclosed, and the privacy safeguards applied to the information collected. Even after updates due to recent data breech and inappropriate sharing of social media user data, social media data privacy and security standards do not meet those required of federal agencies.

The above initial analysis indicates that there exists a tension between federal information and data privacy, quality, accuracy, and security requirements and those of social media platforms. More specifically, there is a significant disparity of intent and use regarding the collection, aggregation, use, and reuse of user data collected by social media platforms and federal agencies. Whereas agencies are restricted to collect data for specific purposes broadly related to the mission of the agency and are limited in how they can use collected data, social media platforms view user data as in essence a commodity to be mined for marketing, business opportunity development, and better understanding of user behaviors - largely driven by micro-targeted ads based on behavioral analytics designed to generate revenue. Federal agencies are specifically prohibited by law and other policies from engaging in these forms of activities.

\subsection{Archiving and Preservation}

Access to and the long-term preservation of government information has long been a centerpiece of US democratic processes in general, and the federal government in particular. For over 150 years, the Government Printing Office has served as the lead and coordinating agency in conjunction with the Federal Depository Library Program (FDLP) - a network of nearly 1150 full, partial, and regional Depositories. This collaborative network has served as the primary means for providing community access to government information. The ability of social media to provide direct interaction between citizens, civil society, and other constituencies and the government, however, has and continues to raise major challenges for the comprehensive collection and dissemination of government information [31, 32]. Initially, the Library of Congress (LoC) indicated that it would harvest and maintain collections of all tweets through twitter. Recently, LoC announced that as of January 1, 2018 it 
would only selectively gather and preserve twitter content [33].

The National Archives and Records

Administration (NARA) has issued guidance regarding the records retention and preservation requirements of electronic records. NARA's Bulletin 2014-02 [34] directs agencies to answer key questions to help determine whether a social media record requires retention: Does it contain evidence of an agency's policies, business, or mission? Is the information only available on the social media site? Does the agency use the tool to convey official agency information? Is there a business need for the information? Positive answers to any of the above are an indication that the content likely is a federal record.

In addition, NARA states that [34]: "social media content may be a Federal record when the use of social media provides added functionality, such as enhanced searchability, opportunities for public comment, or other collaboration." Further NARA indicates that the record must include not just the content, but also the context and structure along with associated metadata (e.g., author, date of creation).

At the request of members of the U.S. Senate, NARA also weighed in regarding whether President Trump's tweets issued on his personal twitter account fall under federal records requirements [35, p. 2]: "NARA has advised the White House that it should capture and preserve all tweets that the President posts in the course of his official duties, including those that are subsequently deleted, as Presidential records, and NARA has been informed by White House officials that they are, in fact, doing so." In short, it is NARA's view that tweets via the President's personal twitter account should be treated as presidential records and preserved. Increasingly federal information and content is "born digital," and its management and long-term preservation have presented any number of challenges for archivist in general and NARA in particular (that discussion is beyond the scope of this article). By and large, however, those electronic records resided within government systems and devices. The advent and increased use of social media by federal agencies, however, introduces new challenges regarding records retention and preservation in several ways: 1) the technology platform resides and is controlled by entities outside government; 2) platform updates and design can impact features and thus preserving the "context and structure", as required by NARA, can be challenging if not impossible; 3 ) the content is continually evolving, thus there may be no true beginning and end to a record; and 4) content can be altered - or even deleted - and thus there is a need to determine which version of a posting on social media is the "official" version or a need to capture all versions including deleted content (as NARA advises). The above challenges are not intended to be exhaustive, but rather illustrative, and it may well be that critical content regarding government functions is lost from the permanent record.

\subsection{Access and Social Inclusion}

Members of the public must be able to access and use social media technologies in order for government use of social media to increase successfully access to government information and services, as well as civic engagement. Several policy instruments are directly related to access and inclusion in social media, including:

- Executive Order 13166 - Improving Access to Services for Persons with Limited English Proficiency. The Executive Order requires that agencies provide appropriate access to persons with limited English proficiency, encompassing all "federally conducted programs and activities," including using social media technologies to communicate and collaborate with members of the public.

- Section 504 of the Rehabilitation Act creates broad standards of equal access to government activities and information for individuals with disabilities, which includes content distributed via social media and establishes general rights to accessible information and communication technologies, which includes social media tools.

- $\quad$ The Telecommunications Act of 1996 promotes the development and implementation of accessible information and communication technologies being used online. Most directly, Section 508 


\begin{tabular}{|c|c|}
\hline Key Policy Goals & Selected Issues and Tensions with Social Media \\
\hline Governing and Governance & $\begin{array}{l}\text { - Agencies must disseminate the same information through } \\
\text { multiple channels. } \\
\text { - Agencies must manage and archive records, regardless of } \\
\text { where records may reside. } \\
\text { - Agencies must provide members of the public without Internet } \\
\text { connectivity with timely and equitable access to information. }\end{array}$ \\
\hline Privacy, Security, \& Data Quality & $\begin{array}{l}\text { - Social media platforms do not conform to federal laws and } \\
\text { regulations governing data privacy. } \\
\text { - Social media platforms do not conform to federal laws and } \\
\text { regulations governing data security. } \\
\text { - Social media platforms do not conform to federal laws and } \\
\text { regulations governing data quality and assurance. }\end{array}$ \\
\hline Archiving and Preservation & $\begin{array}{l}\text { - Social media platform records are dynamic, with content } \\
\text { changing frequently and there is no central archiving } \\
\text { mechanism. } \\
\text { Federal social media retention policies change, e.g., although } \\
\text { the Library of Congress originally committed to capture all } \\
\text { tweets via Twitter, it changed to a selective preservation } \\
\text { approach as of January } 1,2018 \text {. } \\
\text { The National Archives and Records Administration guidance } \\
\text { excludes the retention of much social media content. }\end{array}$ \\
\hline Access and Social Inclusion & $\begin{array}{l}\text { - Internet access is not ubiquitous, nor is the ability to use } \\
\text { Internet-enabled technologies. } \\
\text { Persons with disabilities may be disadvantaged in terms of } \\
\text { accessing government content on social media. }\end{array}$ \\
\hline
\end{tabular}

Table 2. Selected Issues with Social Media.

requires that electronic and information technologies purchased, maintained, or used by the federal government -including third party resources such as social media - meet certain accessibility standards designed to make online information and services fully available to people with disabilities.

Though improving, social media tools can present challenges for persons with disabilities - indeed, for persons with disabilities, social media can mean a reduced ability to participate $[36,37]$. Future technological developments may overcome accessibility challenges, however, federal law and policies require equal opportunity to access and interact with government information content which is not fully possible with government information and services disseminated through social media.

\subsection{Issues and Future Research}

The above policy analysis was not intended to be exhaustive, but rather designed to highlight key issue areas around which there are robust and developed information policies within the U.S. federal government context - and to demonstrate where there are challenges and gaps that social media technologies manifest. Moreover, the above also sought to identify selected issues that surface when social media technologies and online government platforms are manipulated from both within and outside government particularly regarding information and data accuracy and reliability.

Underlying and supporting an open and transparent government is the notion that the actors producing government information, data, services, and resources are acting in good faith and disseminating authoritative and vetted content. It is unclear, however, what influence on the public, policymakers, policy development, policy amendments, changes to law, and other administrative actions that false information posted on social media sites has. Given that such a large percentage of the U.S. public uses social media as a news source [30], and the increased use of social media by policymakers, there is a 


\begin{tabular}{|c|c|}
\hline $\begin{array}{l}\text { Key Policy Goals } \\
\text { and Social Media }\end{array}$ & Selected Research Questions \\
\hline $\begin{array}{l}\text { Governing and } \\
\text { Governance }\end{array}$ & $\begin{array}{l}\text { - What policy structures and frameworks are necessary to govern government use of and } \\
\text { interaction with social media technologies? } \\
\text { - In what ways do social media technologies impact the policy formation process? } \\
\text { - Do social media technologies create expanded or restrict opportunities for engagement } \\
\text { by the public? What situational factors might lead to either expansion or restriction? } \\
\text { Are social media technologies essentially a new branch of government that operates } \\
\text { outside constitutionally-driven policy processes? } \\
\text { - Does the use of social media enable more immersive, interactive, and substantive policy } \\
\text { deliberation? } \\
\text { What collaborative governance processes and structures do social media technologies } \\
\text { enable? }\end{array}$ \\
\hline $\begin{array}{l}\text { Privacy, Security, } \\
\text { \& Data Quality }\end{array}$ & $\begin{array}{l}\text { - Should federal agencies use technology platforms such as social media that do not } \\
\text { - } \\
\text { Shonform to federal privacy, security, and data/information quality standards? } \\
\text { content and content designed to misinform the public and integrity of the electoral } \\
\text { process? } \\
\text { - } \quad \text { Should the federal government regulate social media companies? } \\
\text { - What is the responsibility of federal agencies to ensure that the third-party technology } \\
\text { platforms they use conform to federal privacy, security, and data/information quality } \\
\text { standards? } \\
\text { - Do federal agencies have a responsibility to ensure the privacy of individuals, } \\
\text { particularly when data may not be owned by government agencies? } \\
\text { What measures should government agencies take to ensure that falsified data, } \\
\text { information, and content do not influence or affect policy decisions? } \\
\text { How does the public ensure that federal agencies are not intentionally falsifying released } \\
\text { data, issuing misleading content, removing access to data, or otherwise obstructing } \\
\text { public access to data and information resources? }\end{array}$ \\
\hline $\begin{array}{l}\text { Archiving and } \\
\text { Preservation }\end{array}$ & $\begin{array}{l}\text { - Given that social media tools are increasingly used as a policy development platform, do } \\
\text { all policymaker posts need to be harvested and preserved? } \\
\text { If personal accounts are used, how does one separate personal from government- } \\
\text { related content? } \\
\text { - What is the "document"/content that agencies preserve based on their social media } \\
\text { activities, particularly given the interactive and evolving nature of social media } \\
\text { exchanges? } \\
\text { What is the role of the GPO and the FDLP in the social media technology environment } \\
\text { of the federal government? }\end{array}$ \\
\hline $\begin{array}{l}\text { Access and Social } \\
\text { Inclusion }\end{array}$ & $\begin{array}{l}\text { - How do we ensure that social media technologies are inclusive, particularly for persons } \\
\text { with disabilities, rather than exclusive? } \\
\text { - What tools and approaches best promote universal access to social media technologies? } \\
\text { - How does the public ensure that the federal government is meeting its universal } \\
\text { information access requirements? } \\
\text { How can agencies leverage partnerships to extend social media applications and use } \\
\text { within communities across the country? }\end{array}$ \\
\hline
\end{tabular}

Table 3. Selected Research Questions.

need to explore critically the impact of social media on democratic institutions and processes.

There are a number of questions that would benefit from future research regarding the U.S. government's use of and interaction with social media technologies, as identified in Table 2. On the one hand, the questions in Table 2 identify a number of managerial and operational issues that federal information policies need to address at least in part to offer agencies guidance on how to handle social media-driven communications, engagement, and policy discourse. On the other hand, the questions point to broader issues related to social media's impact on democratic processes. One might argue that the preponderance of academic literature regarding social media - and government rhetoric - focused on overly 
optimistic views of social media, such as engagement, citizen science, and crowdsourcing $[1,7,8,38,39,40,41,42]$.

While that potential and reality exists, it is increasingly also the case that social media has challenged and affected democratic processes and institutions negatively; introduced false information into political discourse to intentionally seek to harm electoral outcomes; and been used by policymakers as a tool to pressure and bully political opponents (Intelligence Community Assessment, 2017; Madrigal, 2018; Sanders \& Patterson, 2018; Mukherjee, 2017). As such, there is emerging evidence that social media can also be harmful to democracies which rely on openness and open platforms that those who would seek to harm individuals and/or democratic institutions can exploit. These aspects of social media technologies in particular require much greater attention and research.

\subsection{References}

[1] Criado, I., Sandoval-Almazan, R., \& Gil-Garcia, J.R. (2013). Government innovation through social media. Government Information Quarterly, 30(4): 319-326.

[2] Porter, J. (2008). Designing for the Social Web. Thousand Oaks, CA: New Riders Press.

[3] Tepper, M. (2003). The rise of social software. NetWorker, 7(3), 18-23.

[4] U.S. Office of Personnel Management. (2017, July). Social Media Policy. Washington, DC: U.S. Office of Personnel Management. Available at: https://www.opm.gov/news/social-media-presence/socialmedia-policy.pdf.

[5] U.S. Department of the Interior. (2010). Social Media Policy. Available at: https://www.doi.gov/notices/SocialMedia-Policy.

[6] U.S. Food and Drug Administration. (2015). Social Media Policy. Available at: https://www.fda.gov/downloads/AboutFDA/AboutThisWebsi te/WebsitePolicies/UCM472486.pdf.

[7] Ambrose-Oji, B., van der Jagt, A. P., \& O’Neil, S. Citizen Science: Social Media as a supporting tool. Available at: https://www.forestry.gov.uk/pdf/Social_Media_Support_Citi zen_Science_April_2014.pdf/\$FILE/Social_Media_Support Citizen Science April 2014.pdf.

[8] Panagiotopoulos, P., Bowen, F., \& Brooker, P. (2017). The value of social media data: Integrating crowd capabilities in evidence-based policy. Government Information Quarterly, 34(4): 601-612.

[9] Bekkers, V., Edwards, A., \& de Kool, D. (2013). Social media monitoring: Responsive governance in the shadow of surveillance? Government Information Quarterly, 30(4): 335342 .

[10] Brabham, D. C. (2008). Crowdsourcing as a model for problem solving: An introduction and cases. Convergence, 14(1), 75-90

[11] Bertot, J. C., Jaeger, P. T., Munson, S., \& Glaisyer, T. (2010). Engaging the public in open government: The policy and government application of social media technology for government transparency. IEEE Computer, 43(11), 53-59.

[12] Jaeger, P. T., \& Bertot, J. C. (2010). Designing, implementing, and evaluating user-centered and citizencentered e-government. International Journal of Electronic Government Research, 6(2), 1-17.

[13] Jaeger, P. T., Paquette, S., \& Simmons, S. N. (2010). Information policy in national political campaigns: A comparison of the 2008 campaigns for President of the United States and Prime Minister of Canada. Journal of Information Technology \& Politics, 7, 1-16.

[14] Orszag, P. (2009, December 8). Open government directive. Memorandum for the Heads of Executive Departments and Agencies. Available at: https://obamawhitehouse.archives.gov/open/documents/opengovernment-directive.

[15] Obama, B. (2012). Digital Government: Building a $21^{\text {st }}$ Century Platform to Better Serve the American People.

Available at:

https://obamawhitehouse.archives.gov/sites/default/files/omb legov/digital-government/digital-government.html.

[16] Sunstein, C. (2010, April 7). Social Media, Web-Based Interactive Technologies, and the Paperwork Reduction Act Memorandum. Available at:

https://obamawhitehouse.archives.gov/sites/default/files/omb /assets/inforeg/SocialMediaGuidance 04072010.pdf.

[17] Mergel, I. (2016). Social media institutionalization in the U.S. federal government. Government Information Quarterly, 33(1): 142-148,

[18] Mergel, I. (2013). Social media adoption and resulting tactics in the U.S. federal government. Government Information Quarterly, 30(2): 123-130.

[19] Snead, J.T. (2013). Social media use in the U.S. Executive branch. Government Information Quarterly, 30(1): 56-63.

[20] Bertot, J. C., Jaeger, P. T., \& Grimes, J. M. (2010). Using ICTs to create a culture of transparency?: Egovernment and social media as openness and anti-corruption tools for societies. Government Information Quarterly, 27, 264-271

[21] Executive office of the President. (2018). Science \& Technology Highlights: The First Year. Available at: https://www.whitehouse.gov/wpcontent/uploads/2018/03/Administration-2017-STHighlights.pdf.

[22] Howard, A. (2016, September 2). How Should History Measure the Obama Administration's Record on 
Transparency? Sunlight Foundation. Available at: https://sunlightfoundation.com/2016/09/02/how-shouldhistory-measure-the-obama-administrations-record-ontransparency/.

[23] Mullin, E., Orcutt, M., Rotman, D., \& Simonite, T. (2017, January). Obama's Technology Legacy. MIT Technology Review. Available at:

https://www.technologyreview.com/s/603316/obamastechnology-legacy/.

[24] Bertot, J.C., Jaeger, P.T., \& Hansen, D. (2012). The impact of policies on government social media usage: Issues, challenges, and recommendations. Government Information Quarterly, 29(1): 371-376.

[25] Mauriello, T. (2017, February 22). Government watchdogs criticize Trump's removal of open data sets. Pittsburgh Post-Gazette. Available at: http://www.govtech.com/data/Government-WatchdogsCriticize-Trumps-Removal-of-Open-Data-Sets.html.

[26] Union of Concerned Scientists. (2017). Sidelining Science Since Day One. Washington, DC: Center for Science and Democracy, Union of Concerned Scientists. Available at: https://www.ucsusa.org/sites/default/files/attach/2017/07/side lining-science-report-ucs-7-20-2017.pdf.

[27] Madrigal, A.C. (2018, June 4). What We Know About Facebook's Latest Scandal. The Atlantic. Available at: https://www.theatlantic.com/technology/archive/2018/06/wh at-we-know-about-facebooks-latest-data-scandal/561992/.

[28] Sanders, J., \& Patterson, D. (2018, May 31). Facebook Data Privacy Scandal: A Cheat Sheet. TechRepublic. Available at: https://www.techrepublic.com/article/facebookdata-privacy-scandal-a-cheat-sheet/.

[29] Intelligence Community Assessment. (2017, January 6). Assessing Russian Activities and Intentions in Recent US Elections [ICA 2017-01D]. Washington, DC. Available at: https://www.dni.gov/files/documents/ICA 2017 01.pdf.

[30] Shearer, E., \& Gottfried, J. (2017). News Use Across Social Media Platforms 2017. Washington, DC: Pew Research Center. Available at: http://assets.pewresearch.org/wpcontent/uploads/sites/13/2017/09/13163032/PJ 17.08.23 soc ialMediaUpdate_FINAL.pdf.

[31] Jaeger, P. T., Bertot, J. C., \& Shuler, J. A. (2010). The Federal Depository Library Program (FDLP), academic libraries, and access to government information. Journal of Academic Librarianship, 36, 469-478.

[32] Shuler, J. A., Jaeger, P. T., \& Bertot, J. C. (2010). Implications of harmonizing e-government principles and the Federal Depository Library Program (FDLP). Government Information Quarterly, 27: 9-16.

[33] Library of Congress. (2017, December 26). Update on the Twitter Archive at the Library of Congress. Available at: https://blogs.loc.gov/loc/2017/12/update-on-the-twitterarchive-at-the-library-of-congress-2/.
[34] U.S. National Archives and Records Administration. (2013, October 25). Bulletin 2014-02: Guidance on Managing Social Media Records. Washington, DC: U.S. National Archives and Records Administration. Available at: https://www.archives.gov/recordsmgmt/bulletins/2014/2014-02.html.

[35] Ferriero, D.S. (2017, March 30). Letter to Senators McCaskill and Carper. Available at: https://www.archives.gov/files/press/press-releases/aotus-tosens-mccaskill-carper.pdf.

[36] Lazar, J. L., \& Wentz, B. (2011). This isn't your version: Separate but equal Web site interfaces are inherently unequal for people with disabilities. User Experience, 10(2).

[37] Wentz, B., \& Lazar, J. L. (2011). Are separate interfaces inherently unequal? An evaluation with blind users of the usability of two interfaces for a social networking platform. Presented at iConference 2011, Seattle, WA, United States.

[38] Chang A., and Kannan P. K. (2008). Leveraging Web 2.0 in Government. Washington DC: IBM Center for The Business of Government.

[39] Drapeau, M. \& Wells, L. (2009). Social software and national security: An initial net assessment. Center for Technology and National Security Policy, National Defense University. Available: http://www.ndu.edu/ctnsp/Def Tech/DTP61

[40] Noveck, B. E. (2008). Wiki-government. Democracy: A Journal of Ideas, Vol. 7.

[41] Osimo, D. (2008). Web 2.0 in government: Why and how? Washington DC: Institute for Prospective Technological Studies.

[42] Snyder, C. (2009). Government agencies make friends with new media. Wired, 25 March. Available: http://blog.wired.com/business/2009/03/governmentagen.html

[43] Mukherjee, S. (2017, June 29). How Cyberbullying and Twitter Attacks Can Wreck Your Mental Health. Fortune. Available at: http://fortune.com/2017/06/29/trump-twittermental-health/.

[44]. Obama, B. Executive Order -- Making Open and Machine Readable the New Default for Government Information. Available at: https://obamawhitehouse.archives.gov/the-pressoffice/2013/05/09/executive-order-making-open-andmachine-readable-new-default-government-. 